\title{
La señorita Lupe. Acercamiento a una novela del ciclo revolucionario
}

Rolando Álvarez Barrón Universidad de Guanajuato

\section{Resumen}

En el presente artículo se analiza la novela La señorita Lupe, de Fortino López Robles, dentro del marco de la novela histórica, la epopeya, la novela ejemplar y el ciclo narrativo de la Revolución mexicana. Se pone especial atención en el proceso de literaturización de la historia y de la literatura como un medio de memoria histórica.

Palabras clave: Revolución mexicana, escuela rural, epopeya, educación, acto narrativo.

\section{Abstract}

This article is based upon the novel La señorita Lupe, written by Fortino López Robles. The analysis focuses upon the topics like Historic Novel, The Epopee, the Cloak-And-Dagger Novel and the narrative cycle configured during the Mexican Revolution. The emphasis is focused on the process of "literaturización" of History and Literature as a way to preserve historical memory.

Keywords: Mexican Revolution, rural school (school out of the cities), Epopee, education, narrative deed. 
C ortino López Robles (1899-1973), originario de Purísima de Bustos, Guanajuato, fue maestro de educación básica, músico, autor del Himno del Instituto de Capacitación del Magisterio y de un curso para la formación docente, Educación Musical, publicado por el Instituto Federal de Capacitación del Magisterio bajo la gestión de José Vasconcelos, autor de un texto histórico, El padre Hidalgo y las primeras rutas de la independencia, y varios artículos publicados bajo el título De tú a tú. Entre su obra literaria destacan: Instantáneas (serie de escritos costumbristas), Amaneceres (memorias de un maestro rural en la Revolución mexicana) y La señorita Lupe (novela de la escuela rural mexicana).

La editorial Cultura de México publicó en 1940 La señorita Lupe, obra que presenta en su transcurso diegético el proceso originario de la escuela rural mexicana, entreverando la idealización de la historia educativa nacional, correspondiente a la segunda década del siglo XX, con la inmediatez cotidiana y la vida privada de los personajes, el paisaje bucólico, a la manera de las tomas fotográficas de Gabriel Figueroa, y la mitificación del maestro rural en la figura de la profesora Guadalupe Gama, protagonista principal de la anécdota. La novela se construye haciendo correr de manera paralela la historia de la escuela rural y la historia de la política y la gestión educativa, la historia del agrarismo y la historia personal de la señorita Lupe.

Contiene elementos que la inscriben dentro del realismo social, muy cercano al realismo socialista soviético, tocando la frontera del testimonio histórico con un fuerte matiz ideológico cardenista y un patente esfuerzo descriptivo documental.

Fortino López: escritor de la Revolución mexicana

Más allá de los escritores antologados por Antonio Castro Leal y a los que las academias literaria e histórica reconocen como los clásicos del ciclo narrativo de la Revolución mexicana, es posible encontrar a 
otros autores que desde un quehacer local abordan en su trabajo novelístico el proceso de la Revolución, iniciado en 1910 y cuyo lindero final es problemático determinar. Tal es el caso del guanajuatense Fortino López Robles, que se inscribe en este género con sus novelas Amaneceres y La señorita Lupe.

Si atendemos a Castro Leal no dudaríamos en afirmar que lo anterior es pertinente de acuerdo al siguiente criterio:

Por novela de la Revolución mexicana hay que entender el conjunto de obras narrativas, de una extensión mayor que el simple cuento largo, inspiradas en las acciones militares y populares, así como en los cambios políticos y sociales que trajeron consigo los diversos movimientos (pacíficos y violentos) de la Revolución, que principia con la rebelión maderista del 20 de noviembre de 1910 [...] (1965:17).

Uno de esos cambios a los que alude Castro Leal, es el de una nueva propuesta educativa que será representada fundamentalmente por el maestro rural, el maestro apóstol y abnegado, el de espíritu cívico a toda prueba y responsabilidad histórica plena, generador de una acción docente de grandes proporciones humanas y sociales, movimiento conocido como la escuela rural mexicana, del que Fortino López es partícipe y que adopta como eje temático de sus novelas, las cuales, nuevamente en atención a los conceptos de Castro Leal, evidencian elementos de orden autobiográfico, de afirmación nacionalista y de carácter épico, según expondremos más adelante.

Es de interés, en el sentido en que presentamos a nuestro autor, detenernos en la dedicatoria de La señorita Lupe, ya que viene a evidenciar la línea ideológica del texto y la filiación política del propio autor: "Al señor general de división don Lázaro Cárdenas, íntegro revolucionario, leal y sincero amigo de los obreros y de los campesinos, iniciador valiente de la independencia económica de México" (López R., 1940: 5). 
Podemos afirmar también que el trabajo literario de Fortino López coincide con el de otros autores del ciclo revolucionario; por ejemplo, la composición de la realidad que hace Rafael F. Muñoz al concentrar en un solo grupo de actores hechos que pertenecen a grupos diversos, también se puede observar con los actores de la novela La señorita Lupe, en ambos casos el proceso literaturizador hace de estos personajes iconos que vienen a representar desde su particularidad anecdótica todo un acontecer de la historia colectiva. Cada uno de ellos más que un sujeto es la síntesis de un colectivo bien definido: los maestros rurales, los campesinos revolucionarios, las autoridades gubernamentales y los reaccionarios; todos presentes de manera unívoca sin lugar a medianías, tal y como los vemos en los murales de Diego Rivera. Con Nellie Campobello comparte el sentido íntimo de la vida cotidiana y la construcción de un ambiente idílico que al alejarse de la mímesis de lo inmediato nos lleva al ámbito psicológico y emotivo de aquellos personajes que contemplan el proceso revolucionario desde la inocencia de la infancia o de la simplicidad campesina, con el matiz de la nostalgia de la memoria que en ambos escritores acusa el sentido autobiográfico. Con Gregorio López y Fuentes lo aúna la visión hacia el futuro nacional desde el análisis de la situación inmediata en un afán de denuncia y de prognosis dentro del proceso de reconstrucción social y afirmación de la nacionalidad en el México que continúa una revolución que ha dejado de ser bélica para convertirse en industriosa, pero que no olvida sus causas inmediatas y mediatas:

País joven, apenas asomado a los albores de un amanecer, en lo político. En lo económico, prolongación de la colonia. País propicio a las nuevas conquistas: Colonia de algunos extranjeros por su riqueza agrícola. Colonia de otros extranjeros por su minoría. Colonia por su sistema ferroviario. Entonces acababa de poner el pie en el país el colonizador petrolero. 
País joven, de historia fácil por sus escasas etapas. Su genealogía no necesita de puntos cardinales a base de jornadas guerreras, ni de fechas exactas. Los ascendientes de Guillermo y Micaela, tres generaciones atrás, bastaban para precisar las capas históricas tal como pueden indicarse las capas genealógicas.

El abuelo, aquel de quien siempre hablaba el finquero, el que militó junto al padre de la Patria, es el punto de referencia más remoto (López y Fuentes, 1939: 55).

Por su parte López Robles, como si diera continuidad al texto de López y Fuentes, inicia su novela de 1940 testimoniando desde una clara conciencia histórica, lo que viene también a impregnar de un sentido épico a su novela:
Año de 1919.
México inicia una nueva etapa de su vida política. La Revolución Social, en lucha abierta contra un régimen autócrata primero, y pos- teriormente contra la reacción, va triunfando en forma definitiva y comienza a cimentar la nueva estructura del País. Todo el mundo siente que nuevas corrientes invaden el espíritu del pueblo; que un nuevo pensamiento y anhelos nuevos conmueven de manera especial a las clases trabajadoras y que un ideal de superación y de mejo- ramiento colectivo comienza a florecer en el alma de los de abajo (López R., 1940: 9).

Así, Fortino López, al igual que los autores del ciclo narrativo de la Revolución mexicana, cumple con el perfil del novelista que define Ralph Fox, citando a Fielding, como un observador atento y crítico de su realidad, el que desde un punto sincrónico es capaz de vislumbrar los extremos diacrónicos de la historia; conceptualización representativa de la teoría marxista y muy especialmente del realismo socialista:

"El novelista, en oposición al cronista, debe usar el método de aquellos escritores que pretenden exponer las revoluciones de los países”. 
Es decir, debe relacionarse con el cambio, con la relación de causa y efecto, con la crisis y el conflicto, y no solamente con la descripción o el análisis subjetivos [...]

[...] alguien que debe poseer la facultad de "penetrar en todas las cosas a nuestro alcance y las posibilidades de conocer y de distinguir sus diferencias esenciales" (Fox, 1980: 113).

Fortino López demuestra esta cualidad a lo largo de su texto y además le otorga un matiz didáctico que acusa su profesión docente, en este sentido también su novela podría catalogarse de ejemplar. Permanentemente hace mención a los valores cívicos y éticos, al deber ser de un nuevo patriota, sus héroes siempre dan muestra de integridad y así resultan ejemplares. Tal es el caso de Luis Falcón, hacendado que entrega su propiedad a los campesinos que la han trabajado por generaciones y que sin decirlo el texto podemos leer entre líneas el cumplimiento del principio zapatista "la tierra es de quien la trabaja":

Por eso, ahora que la vida política de México, su patria tan querida y respetada, se encamina por un sendero de transformación social; ahora que se pretende dividir la propiedad rural para que, suprimido el latifundio, surja la organización agraria y con ella un nuevo bienestar para las gentes del rancho; ahora que se quiere humanizar la condición de los labriegos, dándoles la ocasión de sentirse dueños de la tierra y de sus productos, ya que les asiste todo el derecho, no será Luis Falcón un estorbo, en forma alguna, para que se realice tan avanzado propósito de la Revolución. Allí está la Hacienda de La Noria de las Vueltas. Yo la entrego a los trabajadores porque es de ellos, porque les pertenece, porque es la herencia de sus padres y es también el patrimonio de sus hijos (López R., 1940: 100-101).

El juicio crítico ante la historia, desde la óptica de nuestro autor, sin pretender que sea veraz, siempre resulta congruente con el discurso ideológico en que se inscribe, el de la facción liberal; al tratar sobre 
la Cristiada nos dice el narrador, que en esta novela es de carácter omnisciente:

Es mentira que los "alzados" anden peleando por la libertad de sus creencias; es mentira que pugnen por el reinado de Cristo; lo que sucede es que los latifundistas han armado al brazo de los trabajadores, inventando una persecución religiosa que no existe, para que los mismos trabajadores destruyan las conquistas sociales que la Revolución ha alcanzado en su favor. Allí está el enemigo emboscado: son los poderosos, son las castas privilegiadas, son los tradicionales explotadores del pueblo, quienes han organizado ese Ejército Liberador, como última ignominia cometida a sus víctimas para seguir "reinando" ellos y no Cristo, en nombre de una moral que nunca han tenido (López R., 1940: 110).

Queda el asunto principal de la novela que nos ocupa: la educación social revolucionaria emprendida por el secretario de educación José Vasconcelos y que conforma en sus participantes un ejército que viene a sustituir a la soldadesca revolucionaria sin apartarse mucho del entusiasmo de aquella: los maestros y artistas de las misiones culturales. En su última etapa está el famoso Instituto Federal de Capacitación del Magisterio, al que perteneció Fortino López y en el que dictaron cátedra maestros como Seymour Menton. Uno de los grandes personajes de las misiones culturales fue Fermín Revueltas, vale la pena romper la linealidad de nuestro texto y hacer un meandro alrededor de este personaje tan cercano al movimiento educativo popular revolucionario no sólo en función de acrecentar informativamente este trabajo sino fundamentalmente para profundizar en su explicación, ya que Revueltas es otro icono del quehacer revolucionario de artistas y educadores en la reconstrucción nacional:

Las misiones culturales se proponían unir a los maestros de artes populares (en su gran mayoría pintores) con los campesinos y niños 
lugareños en una cruzada común a favor de la integración de este sector (hasta entonces totalmente marginado) al desarrollo nacional y cultural producto de la institucionalización del movimiento revolucionario. Las ideas principales que animaron este movimiento fueron las de enseñar a los niños a pintar al aire libre, así como la decoración mural de sus salones de clase y escuelas; socializar a la población por medio del teatro de títeres, rescatar el folclor y la artesanía regional. Desafortunadamente fueron muchos los factores que anularon la posibilidad de socializar a grandes núcleos de población en esta cruzada educativa y cultural postrevolucionaria.

Fermín Revueltas adoptó fielmente el credo de las misiones culturales y partió a la Ciudad de Villahermosa, donde realizó la labor de convertir la catedral de esa ciudad en teatro. En su recorrido por otros poblados del estado de Tabasco construyó teatros al aire libre (MAM, 1993: 20).

Hagamos un símil con el texto de La señorita Lupe y encontraremos un cuadro representativo de "los Revueltas" que se diseminaron por el país en éstas “cruzadas", escribe Fortino López Robles:

El maestro de artes plásticas lleva a los maestros rurales a decorar con motivos revolucionarios la sala de cabildos del Palacio Municipal, la sala de actos de la Casa del Agrarista y el salón que se destinará a la Biblioteca Pública. También decoraron los teatros portátiles que los mismos maestros llevarán a sus comunidades. Se hacen trabajos de modelado y de talla directa. Y dicta el misionero muy interesantes orientaciones que servirán para que en las escuelas se fomente y cultive el dibujo, como un valor cultural del pueblo y como una fuerte manifestación ideológica de los niños (López R., 1940: 158).

Quizá, como refiere Antonio Castro Leal de Rafael F. Muñoz, respecto a lo que éste decía sobre los acontecimientos que conforman la trama de sus historias, también podría afirmarse en el caso de Fortino López: en esta historia el autor ha ido componiendo la realidad para 
hacerla más impresionante y elocuente. "Los sucesos referidos son ciertos, uno por uno" (Castro Leal, 1966: 19).

\section{Novela de un posible realismo socialista mexicano}

Veamos en este apartado cómo en el texto de la novela La señorita Lupe, se comprueba lo que hemos afirmado en relación a Fortino López Robles y su quehacer como escritor del ciclo revolucionario.

La obra, desde una lectura analítica, en un primer momento mueve a considerarla como una novela histórica por la fuerza que tienen en ella los sucesos que directamente han sido tomados de la realidad empírica como determinantes del plano del contenido. Y si bien "en el sentido más amplio, toda novela es histórica, puesto que, en mayor o menor grado, capta el ambiente social de sus personajes, hasta los más introspectivos", como dice Seymour Menton (1993, 31-32) la relación cronológica, entre lo que se cuenta y el momento en que se escribe no es lo suficientemente distante como para decir que refiere un pasado, ya que el tiempo de la narración se comprende entre los ańos 1919 a 1926 y la novela sale a la luz en 1940. Sólo median 14 años de distancia entre estas fechas, lo cual impide hablar en rigor, en este caso, de novela histórica según la clasificación ortodoxa, la que - con pequeñas variables en los distintos enfoques teóricos- es unívoca al concebir el pasado como aquellos sucesos "no experimentados directamente por el autor" (Menton, 1993, 32). Lo cual no obsta para que los hechos de la historia revolucionaria y en particular de la educación nacional de la segunda década del siglo $\mathrm{XX}$, aparezcan como una permanente marca de agua a lo largo de la narración.

Veamos algunos ejemplos, en el capítulo VI podemos leer una síntesis de la propuesta educativa gubernamental orientada al sector campesino y que establece el cimiento ideológico e histórico sobre el cual se construye la novela en sus categorías de ficcionalización y de 
producto cultural, en permanente vínculo directo con el movimiento de la Revolución mexicana, visto como un fenómeno bélico, político, místico y estético:

Enero de 1926.

La educación pública, principalmente en los medios rurales, ha alcanzado un fuerte desarrollo, virtud a lo cual el gobierno nacional tiene vivo interés en asegurar el éxito de la obra cultural emprendida por la Revolución para beneficio casi privativo de las masas trabajadoras. Desde fines de 1921 a fines de 1924, durante la administración del Presidente Obregón y siendo titular de la Secretaría de Educación el licenciado José Vasconcelos, ha venido trabajándose tenazmente por resolver los principales problemas que impiden el desarrollo de la cultura popular [...] A principios de 1925 y ya bajo la administración del Gral. Calles [...], se ha establecido el Departamento de Escuelas Rurales e Incorporación Cultural Indígena que, como su nombre lo indica, tiende a realizar una obra educativa que abarque por igual al campesinado mestizo e indio, con tendencia a la fusión de ambas ramas como un postulado de integración social. La Revolución mexicana desea en esta forma cumplir una de sus más altas promesas [...], las miradas de todo el mundo están puestas en esta cruzada social emprendida con tanto carińo [...] (López R., 1940: 42-44).

En este sentido, la novela de Fortino López tiene una vocación historicista innegable, contiene elementos informativos de pretendida veracidad que obligan a ser leídos más que como ficción literaria como crónica historiográfica, sin que esto implique que se reduzcan a tal categoría como elementos formantes de la ficción. Estamos ante una visión microhistórica de la vida del maestro rural y del campesino mexicano, considerado el primero como apóstol del progreso y de la unificación de México y el segundo como la fuerza fundante y fundamental del México revolucionario. A la vez encontramos en la novela una relación del trabajo emprendido desde el gobierno para la forma- 
ción profesional de aquellos docentes de la Escuela Rural Mexicana carentes de un perfil pedagógico formal, insuficiencia que en estos casos los docentes suplían con una vocación irrestricta de entrega al trabajo y a la "misión histórica" que la patria les había encomendado. Estamos hablando de los Institutos Normales que eran parte de las Misiones Culturales de la Secretaría de Educación y que más tarde constituirían el famoso Instituto Federal de Capacitación del Magisterio, adscrito a la Dirección de Enseñanza Superior e Investigación Científica, por decreto del presidente de México, Manuel Ávila Camacho, en 1944.

Los personajes de la novela de Fortino López son una recreación fidedigna de estos maestros improvisados que a través de la Misión Cultural, en un primer momento, y del Instituto de Capacitación, con posterioridad, constituirán una comunidad educativa ejemplar en la historia no sólo de México sino de Latinoamérica y que por desgracia, en la segunda mitad del siglo pasado, veremos extinguirse en el marasmo de un proceso de burocratización y mediocre politiquería del sector educativo. Pero aquellos maestros, a los que Guadalupe Gama representa, son una realidad en nuestra historia mexicana. No es la ficción la que los inventa, sino es ésta sólo un medio para testimoniarlos. Fortino López, en franca ipseidad, construye a sus personajes con absoluto conocimiento de causa y más que la voz de un literato, encontramos en la voz autoral la de un maestro recreando su propia realidad (argumento que, visto desde la ortodoxia de los géneros, abona en contra de la tipificación de novela histórica para esta obra). Hay en Fortino López, a la par de una inventiva literaria, una rememoración biográfica y un "conocimiento" anticipado de la historia, es decir que en ella se prospecta con claridad el rumbo del proceso magisterial de al menos dos décadas posteriores inmediatas al tiempo de la novela. Y si la visión de la obra no hubiera sido retrospectiva sino prospectiva, entonces la condición de novela histórica sería incuestionable. Ya que el futuro, narrado ficcionalmente como 
un resultado directo del pasado, también se considera factor constitutivo de este género. Podemos encontrar un argumento a favor de este sentido prospectivo de la historia en la novela si recordamos las palabras de Jaime Torres Bodet, Secretario de Educación, con motivo de la promulgación de la ley que crea a este instituto, el 26 de diciembre de 1944 (cuatro años más tarde de la publicación de La señorita Lupe). Es importante notar el tono afín entre el fragmento citado de la novela y el que se reproduce aquí.

Uno de los más agudos problemas de la Secretaría de Educación Pública ha sido desde hace tiempo, el que deriva de la falta de capacitación profesional de la gran mayoría de los maestros rurales que prestan sus servicios a la Federación. No obstante los esfuerzos realizados, puede decirse, en términos generales, que 9,000 de dichos maestros sólo poseen un certificado de educación primaria. De los 9,000 restantes, cerca de 3,000 han hecho un año o dos de estudios secundarios, aproximadamente 4,000 están graduados en escuelas normales rurales y, sólo 2,000 han sido formados en escuelas normales urbanas de plan completo (SEP, 1945: 11).

Es evidente que el texto de Fortino López es una sombra de las palabras de Vasconcelos. Otro punto interesante de comparación entre la literalidad de la realidad y su literaturización está en el sesgo ideológico de proletarismo que evidencia la novela: maestros, campesinos y obreros son todos una misma categoría trabajadora. En el capítulo XXIV, intitulado “¡Avanza, juventud!”, hay toda una elegía al trabajo y al obrero, entendiendo por éste tanto al trabajador manual como al intelectual y al artista, inspirado por un sentido de solidaridad social o quizá más precisamente socialista, ambiente que se respira durante el cardenismo en el país, una visión utópica del México en reconstrucción donde las clases sociales se diluyen hasta polarizarse sólo en revolucionarios y conservadores. No hay puntos intermedios, es una sociedad que recuerda a las primitivas comunidades cristianas 
donde la voz del absoluto (en aquel caso Dios y en éste la Revolución) parece sentenciar "estás conmigo o estás contra mí", apuntando, irremediablemente, hacia un dogmatismo histórico:

Día primero de mayo [...]:

Comienza este mes con una plegaria al trabajo. La plegaria de la gleba, que armoniza su canto de lucha con la música solemne de los yunques. La voz rebelde de las muchedumbres proletarias [...].

Soldados de la Revolución, viejos campesinos que ayer fueron a los campos de batalla a conquistar los derechos de su clase. Nutridas caballerías de ejidatarios, armados y equipados, para defensa de la Tierra y sostenimiento de las instituciones ciudadanas. Enjambre de obreros, prole sindicalista unida fuertemente en un supremo anhelo de afianzamiento de la justicia social, que es precio de su dolor y precio también de la sangre de quienes se inmolaron en aras de su causa común (López R: 225-226).

$\mathrm{Y}$ junto a este fragmento elegiaco el autor hace una descripción del acto cívico con una precisión de datos que avasallan al lector y que por momentos parecería que ponen en peligro el hilo de la fábula. $\mathrm{Su}$ expresión es plástica y nos lleva al ámbito de lo visual a través de los detalles descriptivos, estereotipo de las ceremonias cívicas escolares, la novela en este aspecto cobra una fuerza de realismo casi total y es irrebatible que la visión del autor pasa de la construcción ficticia a la remembranza y la recreación del profesor experto que es él, aunque desde luego no se refiere a una ceremonia en particular, ésta, la que describe, sintetiza todas las que se celebran bajo los gobiernos revolucionarios, al menos hasta los años de la década de 1960. Una escenografía que se repite en cada rincón del país para representar la unidad nacional construida sobre una historia que a base de un proceso emotivo generado desde un discurso oficialista, retórico y mitificante; es aceptada de manera dogmática por el pueblo. Me permito la cita, pese a su extensión considerable, ya que resulta altamente ilustrativa de lo que estamos hablando: 
Llegan el Gobernador del Estado y otros altos funcionarios [...]. Los clarines de la guardia tocan "marcha de honor". Suena el Himno Nacional con todo su esplendor y aviva en los corazones el noble sentido de la Patria. Y al terminar el canto guerrero de los mexicanos, estalla un aplauso solemne y uniforme [...].

Se inicia el programa.

Cuatrocientos nińos, de uno y otro sexo, colocados en el centro del estadio, cantan el "Corrido del Sol" y "Te vengo a decir adiós".

Un grupo de quinientas nińas, uniformadas de blanco y rojo, ejecutan una tabla de gimnasia, al compás del vals "Sobre las Olas".

Por el fondo avanza una columna de cuatro en cuatro, con banderas blancas con inscripciones rojas. Al frente van nueve muchachas, con faldas rojas, blusas blancas y gorritas de cuartel, rojas también; una de ellas lleva la bandera de los atletas; las otras forman su escolta. Los de la fila son en número de mil doscientos. Vienen marcando el paso, con garbo singular y apostura. Los tambores llevan el compás. Caminan de frente hacia la tribuna donde se encuentran los que presiden el festival [...] Los componentes de la columna visten uniforme de atletas: pantalones cortos de color blanco, camiseta blanca con una cifra progresiva, zapatos tennis (López R: 227-228).

Hasta aquí es posible, de manera general, evidenciar la intención de la novela como un testimonio de la historia que rebasa las limitantes historiográficas impuestas por un principio de verdad no siempre riguroso, también podemos comprobar que la obra se inscribe en una ideología que es propia de la escuela socialista:

Estos que ahora vienen, con paso solemne y marcial, son los de la nueva generación; muchachos agraristas; hijos de la escuela rural; productos de la Revolución; gentes que han acrisolado su pensamiento en el laboratorio de la investigación, con la antorcha del razonamiento personal, y que se sienten libres, más libres que las generaciones que ayer fueron carne de explotación y cuyo dolor engendró 
las ansias de la lucha redentora. Las banderolas son los distintivos que indican el Ejido de donde procede cada grupo. Aquí están representados todos los poblados agrarios del estado. Su concentración es el triunfo más alto que obtiene la organización campesina; es una demostración de los adelantos culturales de la escuela socialista (López R:, 1940: 229).

\section{La línea de ficción}

Guadalupe Gama es el nombre de la heroína de esta novela, en torno de su historia personal se teje la visión histórica de 10 años de vida nacional. Como todo héroe, la nuestra surge de un ámbito de adversidad, en este caso la marginalidad y la orfandad, y desde allí se levanta en pie de lucha, sin tregua ni cuartel, contra un destino que apuntaba a ser determinantemente adverso para cumplir con el verdadero que es el de su heroicidad. Se convierte en la señorita Lupe. Maestra rural ejemplar, activista social en favor de las causas más difíciles: la lucha agraria, la lucha por las mujeres, la defensa de la Revolución, la defensa de su amor y de su integridad. Pero como todo héroe que apunta a la trascendencia debe cumplir con el pago de un precio milenariamente establecido: la propia vida.

Después de conquistar todos los triunfos, llega la fatalidad y la consagración como consecuencia, la historia que se repite una y otra vez, el patriota traicionado como el caso de Viriato o el toreador que muere en la plaza como Sánchez Mejías. La señorita Lupe muere en un hospital a causa de un accidente ferroviario.

La intriga es una historia de amor o mejor dicho la de una mujer enamorada. Enamorada de un hombre, de los nińos, de los campesinos y campesinas, de la Revolución y de la patria:

Cuando Lupe Gama se da cuenta de lo que se está haciendo, cuando sabe que en muchos ranchos de los contornos ya se han establecido escuelas [...] ella que por los azotes que la vida le ha dado está ple- 
namente amalgamada en el dolor con los de abajo, ella, que por intuición siente impulsos de estar al lado de los humildes y luchar con ellos, ella que está predestinada para realizar los bellos ideales que se ha forjado y que no ha perdido la esperanza de contribuir a la redención de sus amigos los rancheros, toma valientemente la resolución de ir a ofrecer sus servicios para convertirse mentora de campesinos sentando plaza de maestra rural (López R, 1940: 229).

Esa decisión va a detonar toda la intriga, va adquirir tonos epopéyicos cuando alrededor de esta mujer el mundo interior y el mundo exterior se amalgaman para construir la aventura eterna del bien contra el mal. Un pequeño grupo de campesinos en torno a una maestra redentora lograrán reconvertir su destino trágico en un acto triunfal. Y ella pasará de la dimensión histórica a la mítica y su nombre será el nombre de su pueblo:

La señorita Lupe murió ayer.

El salón de Cabildo del Ayuntamiento fue convertido en capilla ardiente, han desfilado frente a su cadáver grandes núcleos de campesinos, de obreros, de niños y de mujeres [...].

Ayer mismo convocó la Presidencia Municipal a todo el pueblo a un plebiscito urgente [...], con objeto de solicitar que, con dispensa de trámites se decrete el cambio de nombre del Pueblo, como un merecido homenaje a la memoria de la maestra M. Guadalupe Gama.

\section{DECRETO NUMERO 14}

Artículo primero.- El pueblo de Tepeguajes, cabecera del Municipio del mismo nombre, se denominará en lo sucesivo VALLE DE GUADALUPE...

\section{Conclusión}

Hasta aquí se ha intentado un acercamiento a la novela de Fortino López R. desde una óptica situada en el realismo social y la testi- 
ficación histórica desde la ficción. Se presentaron, desde el propio texto, elementos que puedan evidenciar esta vocación en el autor y proponer la posibilidad de una novela del ciclo de la Revolución, inscrita en un posible realismo socialista mexicano, tomando en cuenta sus estructuras intertextuales dadas entre el discurso de la historia y el discurso literario, quizá en un fenómeno análogo al cubismo del Retrato zapatista de Rivera.

El objetivo más que agotar el texto de esta obra ha sido abrir una posibilidad investigativa desde un autor local sobre un fenómeno universal, el de la novela histórica revolucionaria que aborda el tema del campesinado y sus relaciones con otras de carácter similar, pensemos en Los campesinos, de Balzac. Así, este artículo, es sólo un intersticio estrecho que mira hacia un panorama amplísimo y complejo.

\section{Bibliografía}

Carpentier, Alejo et al., 1985, Historia y ficción en la narrativa hispanoamericana, Venezuela, Monte Ávila.

Castro Leal, Antonio, 1965, La novela de la Revolución mexicana, vol. I, México, Aguilar.

, 1966, La novela de la Revolución mexicana, vol. II, México, Aguilar.

Filinich, María Isabel, 1997, La voz y la mirada, México, Universidad Iberoamericana/Plaza y Valdez.

Fox, Ralph, 1980, La novela y el pueblo, México, Nuestro Tiempo.

López y Fuentes, Gregorio, 1939, Huasteca, México, Botas.

López R., Fortino, 1928, Instantáneas, México, Cultura. , 1937, Amaneceres, México, Cultura. , 1939, De tú, a tú, México, Cultura.

, 1940, La señorita Lupe, México, Cultura. 
1973, El padre Hidalgo y las primeras rutas de la insurgencia, México, Compañía editorial, impresora y distribuidora.

Lukács, Gÿorgy, 1989, Sociología de la literatura, trad. Michael Faber Kaiser, Barcelona, Península.

MAM, 1993, Fermín Revueltas 1902-1935, México, Museo de Arte Moderno.

Menton, Seymour, 1993, La nueva novela histórica de la América latina [sic] 1979-1992, México, FCE (Popular, 490).

Perus, François (comp.), 1997, Historia y literatura, México, Instituto de Investigaciones Dr. José Ma. Luis Mora.

Ricoeur, Paul, 1996, Si mismo como otro, trad. Agustín Neira, México, Siglo XXI.

SEP, 1945, Boletín informativo, núm. 1, México, Instituto Federal de Capacitación del Magisterio. 